\title{
O PET COMO INSTRUMENTO DE INTEGRAÇÃO ENTRE O ENSINO MÉDIO E A UNIVERSIDADE
}

\section{Uma análise das Aulas de Nivelamento}

\author{
João Paulo M. Couto1; Adriane M. C. Araújo2; Diego L. Moreira2; \\ Wanderson F. Maia3; Alex S. C. de Souza4. \\ 1 PETiano discente (bolsista) do grupo PET Civil - UFSCar e discente do curso \\ Engenharia Civil da Universidade Federal de São Carlos \\ 2 PETiano discente (não-bolsista) do grupo PET Civil - UFSCar e discente do \\ curso Engenharia Civil da Universidade Federal de São Carlos \\ ${ }^{3}$ PETiano tutor do grupo PET Civil - UFSCar e docente do Departamento de \\ Engenharia Civil da Universidade Federal de São Carlos \\ ${ }^{4}$ Ex PETiano tutor do grupo PET Civil - UFSCar e docente do Departamento \\ de Engenharia Civil da Universidade Federal de São Carlos
}

\begin{abstract}
PET Civil, Universidade Federal de São Carlos, São Carlos, São Paulo.
\end{abstract}
Palavras-chave: Ensino; Integração; PET; nivelamento.

\section{Introdução}

No histórico recente da educação brasileira, diversas ações governamentais agiram em torno da democratização do ensino superior, ampliando o acesso à universidade por diferentes estratos econômicos da sociedade (FLORES 2017). Seja pela simples expansão das vagas nas universidades públicas ou pela utilização de ações afirmativas previstas na Lei no 12.711 , o ingresso de estudantes com diferentes históricos sociais e educacionais se tornou cada vez mais comum.

Nesse contexto, foi observado pela comunidade acadêmica, e em especial o PET Civil - UFSCar, uma crescente dificuldade de adaptação dos estudantes 
ao ritmo e grade das disciplinas dos primeiros semestres da graduação. Dentre os diversos motivos envolvidos nas altas taxas de reprovação em disciplinas de matemática e física, o grupo observou que a incongruência entre a qualidade do ensino básico e médio com o ensino superior se destaca como um dos maiores obstáculos entre os alunos ingressantes, principalmente os vindos de escolas públicas (DE FARIAS et. al 2015.). A falta de base escolar e a diferença de conhecimento prévio entre colegas da mesma turma tornavam clara a necessidade de uma equalização do nível dos alunos.

Dessa forma, em 2015, o Programa de Educação Tutorial do curso de Engenharia Civil da Universidade Federal de São Carlos (UFSCar) desenvolveu como atividade institucional as chamadas "Aulas de Nivelamento", onde PETianos preparam e ministram aulas voltadas às disciplinas de Cálculo 1, Física 1 e Geometria Analítica, com carga horária total em torno de 8 horas, resgatando conceitos do ensino médio e integrando-os com os primeiros tópicos abordados no ensino superior das grades de ciências exatas.

Concebida inicialmente como atividade voltada para o apoio dos estudantes ingressantes no curso de Engenharia Civil, sua expansão vem ocorrendo anualmente e hoje sua realização é antecipada por calouros de diversos cursos. Agora, aproximando-se da sua quinta edição, é importante avaliar o impacto das aulas de nivelamento dentro da universidade e o papel do Programa de Educação Tutorial frente à realidade da disparidade de qualidade nas diferentes etapas do ensino público brasileiro.

\section{Metodologia}

As edições das aulas de nivelamento discutidas nesse trabalho foram realizadas nos anos de 2015, 2016, 2017 e 2018, através dos relatórios elaborados pelos PETianos envolvidos em cada uma, além de fotos, feedbacks, enquetes e outros registros realizados a cada ano. A realização da atividade pelo grupo pode ser conceitualizada da seguinte maneira, através do mapa de processos e do fluxograma nas figuras 1 e 2 , respectivamente:

Figura 1: Mapa de processos das aulas de nivelamento. 


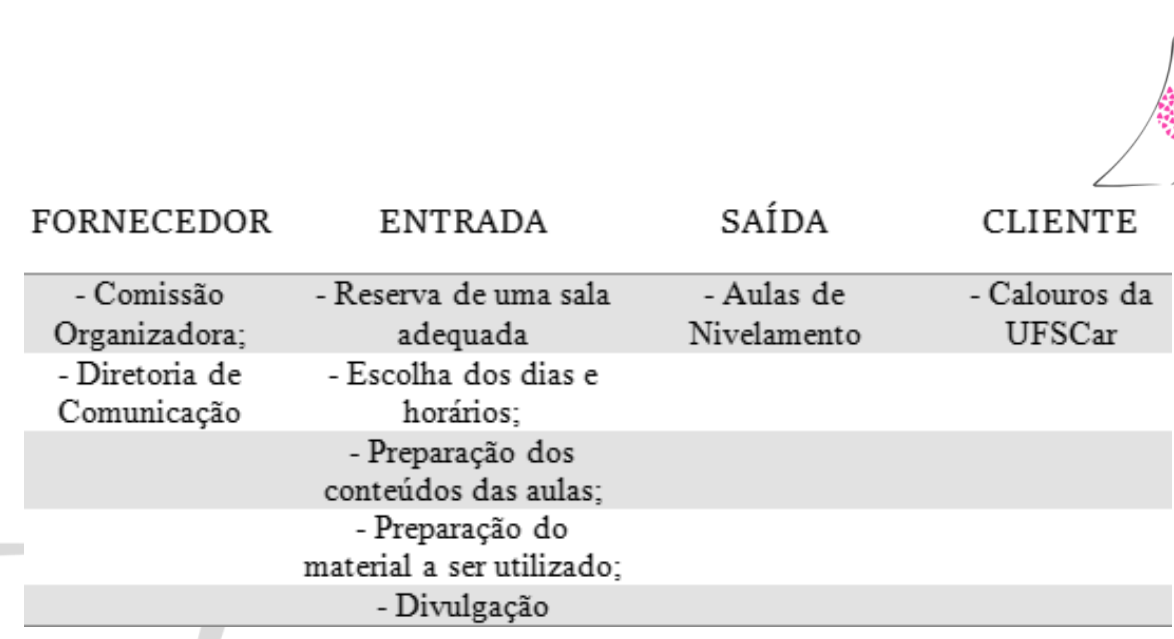

Fonte: Grupo PET Civil - UFSCar, 2018.

Figura 2: Fluxograma de realização das aulas de nivelamento.

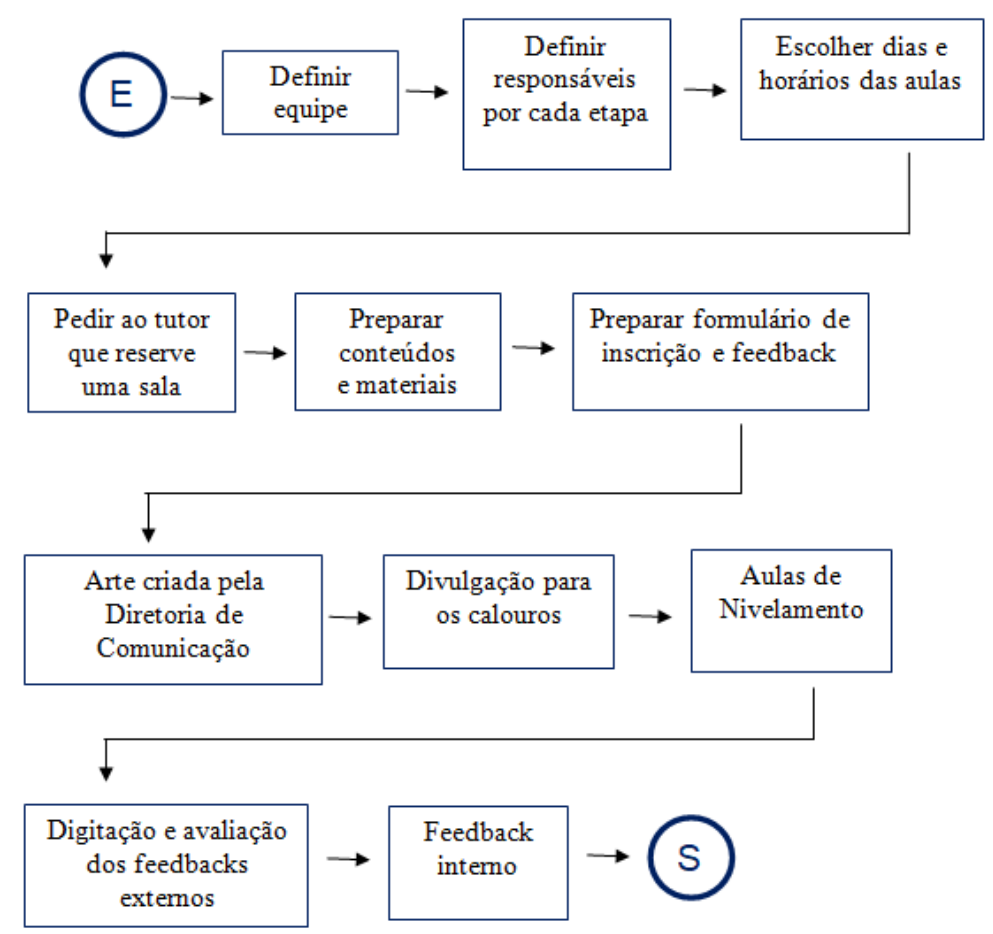

Fonte: Grupo PET Civil - UFSCar, 2018.

A partir disso, foram utilizados os Relatórios de Atividade e os Feedbacks desenvolvidos em cada ano para se avaliar os diferentes aspectos da realização das aulas de nivelamento, desde suas datas de realização, quantidade de participantes e o conteúdo abordado até a avaliação dos participantes e as perspectivas para o futuro da atividade.

\section{Resultados e discussão}

Durante as primeiras edições da atividade, as aulas de nivelamento tinham divulgação e ementa preparadas apenas para os ingressantes do curso de 
Engenharia Civil. A partir dos feedbacks recebidos e da confiança dos PETianos com a organização das aulas, a edição de 2018 foi preparada e divulgada para toda a comunidade acadêmica da UFSCar, sendo possível observar o abrupto aumento do número médio de participantes nos dias de aula, conforme a Figura 3.

Figura 3: Média de participantes diários por edição do evento.

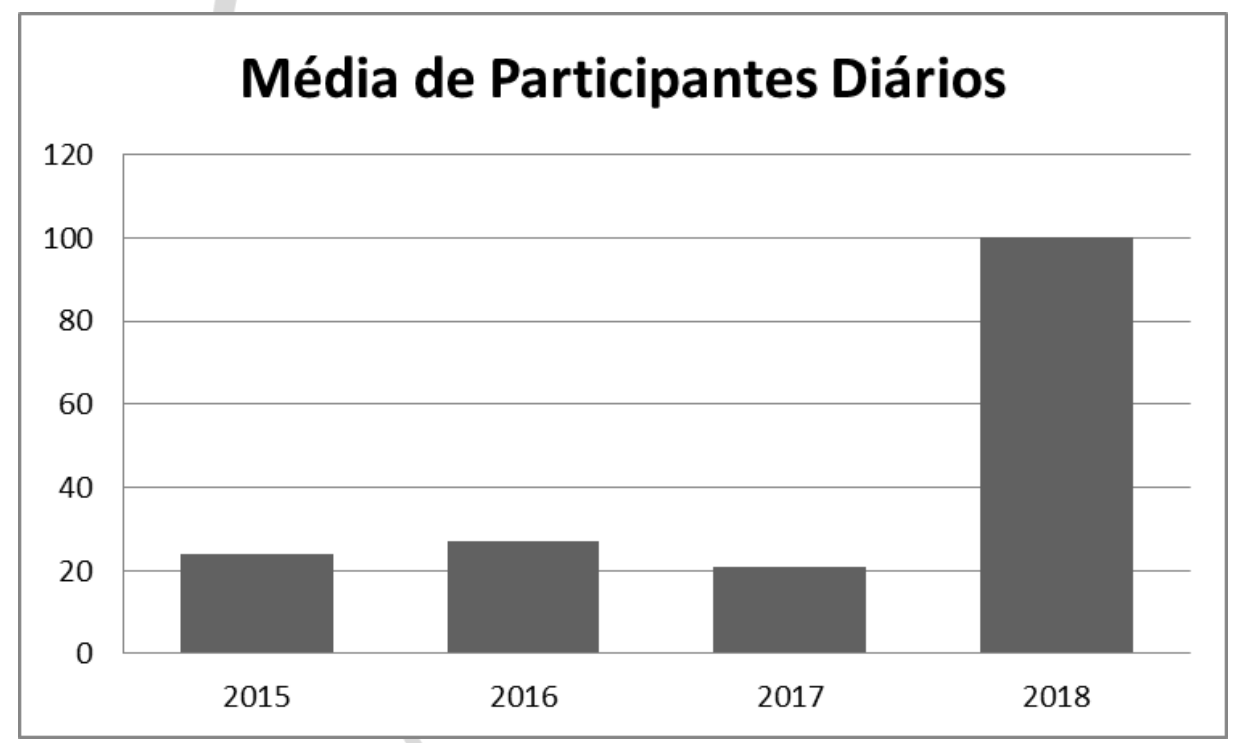

Fonte: Elaborado pelos autores.

O grande número de participantes na edição aberta à toda comunidade acadêmica indica a demanda dos ingressantes de possuírem esse acompanhamento logo nas primeiras semanas de aula, demonstrando que 0 problema de incongruência entre o ensino médio e superior é comum e conhecido. Além disso, as datas das aulas de nivelamento flutuaram entre as primeiras semanas de aula, já que as tutorias realizadas em cada disciplina pela própria universidade só se estabelecem após o primeiro mês e não abordam necessariamente tópicos do ensino médio.

Foi avaliada também a qualidade das aulas segundo avaliação anônima dos participantes através de ficha de Feedback com notas de 1 a 5, como demonstrado na Figura 4. A evolução ascendente nas avaliações indica que o grupo incorporou as recomendações dos participantes dos anos anteriores, incluindo nas aulas resoluções de exercícios, dicas de estudo e comportamento, e preparando e melhorando o material didático distribuído. 
Figura 4: Avaliação das aulas por edição do evento.

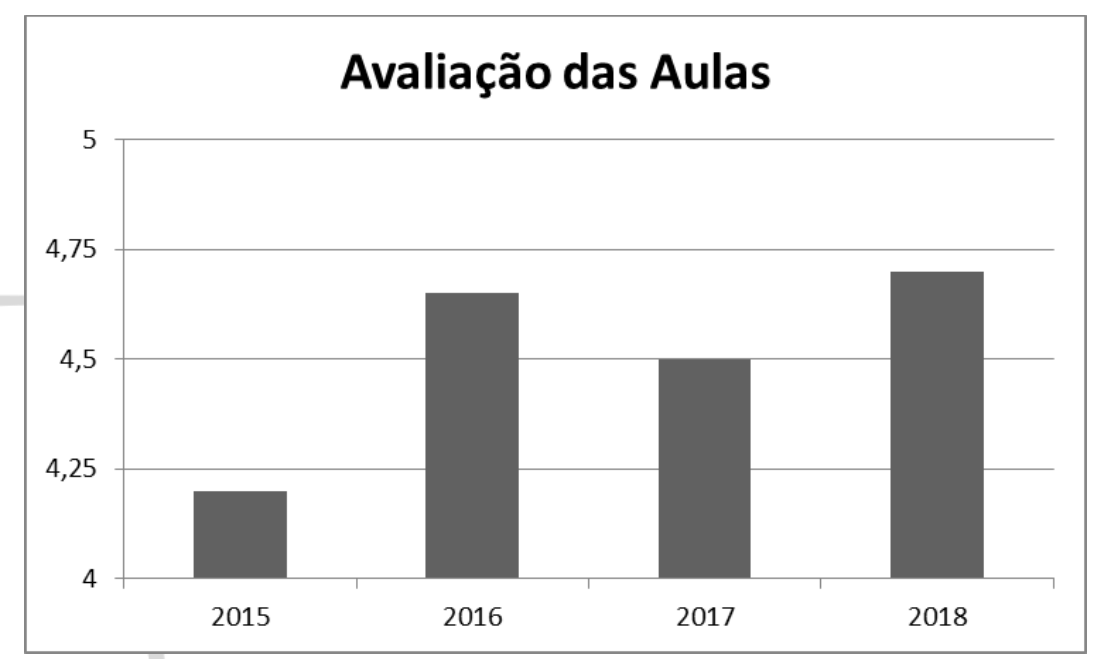

Fonte: Elaborado pelos autores.

Além da avaliação das aulas, outras informações são coletadas na ficha de Feedback, como horário e duração da atividade, além de um espaço aberto para recomendações. Esses dados são utilizados pelo grupo para organização da edição seguinte, buscando melhorar e facilitar a participação da atividade pelo máximo de alunos possíveis.

Figura 5: Calouros assistindo às aulas de nivelamento.

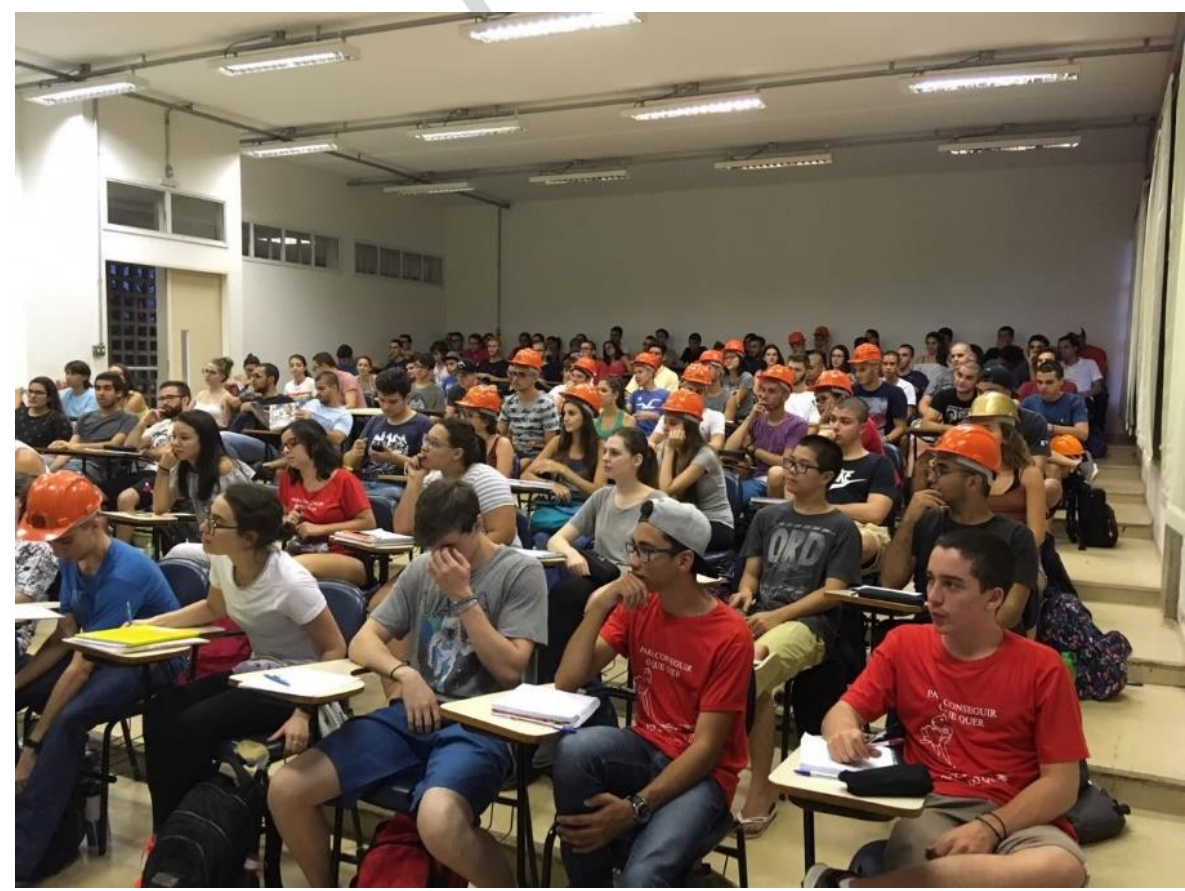

Fonte: Grupo PET Civil - UFSCar, 2018. 
Além do papel obviamente didático das aulas de nivelamento, foi notado outro importante aspecto da atividade: acolhimento aos calouros. Foram recorrentes em todas as edições diversos agradecimentos pelo apoio e tratamento humanizado durante as aulas, que ocorrem logo no início de uma árdua graduação. Também foi notada a importância do evento para a divulgação do grupo PET Civil na universidade, apresentando a diversos alunos um exemplo de projeto com qualidade e organização. Dessa forma, ficou claro aos calouros que encontram no Programa de Educação Tutorial um parceiro na transição entre o ensino médio e a universidade, recebendo apoio acadêmico e humano durante sua estadia na UFSCar.

\section{Conclusões}

A transição do ensino médio para a universidade é árdua em diversos aspectos, e as diferenças do ponto de vista acadêmico são as mais citadas como motivo de reprovação e desistência. Dessa forma, o Programa de Educação Tutorial deve ir além das tradicionais iniciativas de integração social (como gincanas e calouradas) e buscar maneiras de integrar e preparar os estudantes para a graduação, oferecendo apoio e suprindo deficiências prévias na educação. Portanto, iniciativas de sucesso como as aulas de nivelamento demonstram a possibilidade do PET contribuir como ponte entre o ensino médio e um ensino superior de sucesso.

\section{Referências}

FLORES, Sharon Rigazzo. A democratização do ensino superior no Brasil, uma breve história: da Colônia a República. Revista Internacional de Educação Superior, Campinas, SP, v. 3, n. 2, p. 401-416, jul. 2017. ISSN 24469424. Disponível em: <https://periodicos.sbu.unicamp.br/ojs/index.php/ riesup/article/view/8650611/16824>. Acesso em: 17 jan. 2019.

DE FARIAS et al. Diagnóstico de Reprovações dm Cálculo 1, Geometria Analítica e Física 1 dos Alunos de Engenharia Civil da UFSCar e Aulas De

Nivelamento. III Congresso Nacional dos Grupos PET de Engenharia Civil. Curitiba, 2016. 